\title{
The Relationship between Cultural Intelligence and the Attitudes towards Refugee Students: A Study on Primary School Teachers
}

\author{
Sedat Alev \\ Ministry of National Education, Gaziantep, Turkey, ORCID: 0000-0003-4506-4756 \\ Mevlüt Kara* \\ Educational Sciences, Gaziantep University, Gaziantep, Turkey,
} ORCID: 0000-0002-6381-5288

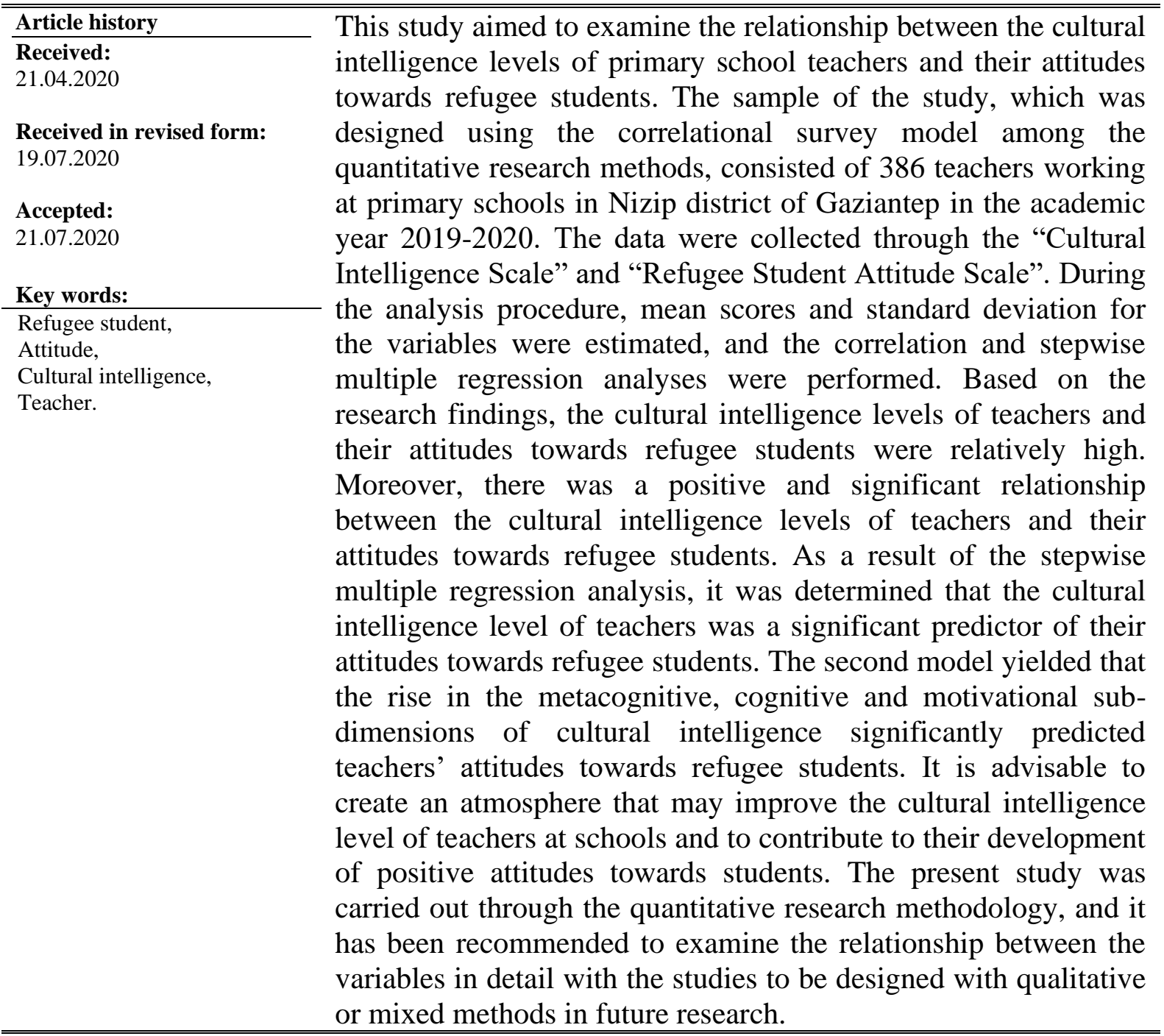




\section{Introduction}

People were forced to leave their geographies from past to present due to various reasons (financial problems, wars etc.). As a result of migrations, they interacted with different cultures and influenced cultural, social and economic characteristics of the communities they came across (Ünal, 2014). The civil war in Syria in recent years and the emergent chaotic atmosphere have caused millions of people to migrate to different countries and to be asylum-seekers (K1lcan, Çepni \& K1lınç, 2017). It has been known that Turkey is among the mostly emigrated countries by the Syrians due to its geographical location. The forced migration from Syria to Turkey beginning with the refugee group of 252 people on the 29th of April 2011, has turned into a mass immigration movement with the growth of conflicts displacing millions of people fleeing the war (Akşit, Bozok \& Bozok, 2015). The majority of refugees who have migrated to Turkey consists of children under the age of 18 (Kilcan et al., 2017). In this regard, the migration movement has started to be considered as a serious problem in terms of access and integration of refugee children into education, as well as causing economic and social issues. The practices initiated by the Ministry of National Education (MoNE) aimed at the training of preschool and primary school first grader refugee students in public schools who had been formerly educated at the Temporary Education Centres (TECs) to facilitate their integration both into society and education can be regarded as an outstanding attempt towards solving the problems in the field of education.

It can be observed that the relevant literature includes various studies devoted to refugee students (Aydin \& Kaya, 2017; Block, Cross, Riggs \& Gibbs, 2014; Börü \& Boyac1, 2016; Çelik \& İçduygu, 2019; Jafari, Tonga \& Kışla, 2018; Kılcan et al., 2017; Taylor \& Sidhu, 2012). Aydin and Kaya (2017) conducted a study on the educational requirements of Syrian refugee students' and the barriers for their access to education in their qualitative research. Block et al. (2014) concluded that the social and emotional needs of refugee students should be focused on and the schools should facilitate the learning of refugee students. Börü and Boyac1 (2016) discussed the problems of refugee students at schools, Kilcan et al. (2017) developed an attitude scale towards refugee students, and Taylor and Sidhu (2012) investigated the role and contribution of education on the integration of refugee students. The overall examination of the studies indicated that they focused on the integration of refugee students into education. In this regard, it is possible to allege that primary school period has an important role in ensuring integration. That's why, integrating children of this age into education will contribute to have lesser problems in later periods. As a matter of fact, Sağlam and Kanbur (2017) pointed to the importance of the primary school age, in which basic knowledge and skills have been given, and the infrastructure of complex learning has been created for the ability of refugee students to hold on to life and to love the country they migrated to. Therefore, it can be claimed that primary school-age refugee students' receiving education together with their peers of different cultural backgrounds is influential not only in their cognitive and affective development but also in their socialization and integration processes.

It has been acknowledged that the schools play a crucial function to create the culture of living together in the societies consisting of individuals with different cultural backgrounds. In fact, students spend most of their time at school without their families to improve their social and cognitive skills (Chiu, Pong, Mori, \& Chow, 2012). However, Vedder, Horenczyk, Liebkind and Nickmans (2006) argue that the schools cannot meet the social, cultural and academic needs of refugee students satisfactorily, and it is one of the fundamental educational problems of today's world. It is supposed that the attitudes and behaviors of teachers play an 
important role for the solution to this problem besides their professional competencies. To that end, the increasing number of students with different cultural backgrounds in the classroom necessitated teachers to adapt the knowledge, skills and attitudes they had for the challenges that may arise in different contexts and to create an encouraging atmosphere for all students to learn (Ladson-Billings, 1995; Wubbels, Den Brok, Veldman \& Van Tartwijk, 2006). It can be asserted that teachers' having the skills referring to cultural intelligence such as communicating with students from different cultures, problem-solving and orientation is vital in the process of creating this sort of a learning environment in addition to their professional competencies.

It is observed that cultural intelligence has been emphasized as well as emotional intelligence in recent studies dealing with the theoretical and empirical foundations of intelligence (Keung \& Rockinson-Szapkiw, 2013; Mahasneh, Gazo \& Al-Adamat, 2019; Petrović, 2011). Cultural intelligence can be described as an area of intelligence that is proposed to explain the differences between people in terms of their ability to contact with other societies and also with various cultures within their society (İlhan \& Çetin, 2014). Cultural intelligence has been redefined in the literature such as the ability to adapt to novel cultural contexts (Earley \& Ang, 2003), a sophisticated competency including cultural knowledge, awareness and behavioral skills (Arastaman, 2018) or the ability to interact successfully with people of different cultures (Ang at al., 2007; Thomas, 2006). The individuals with high level of cultural intelligence establish trust-oriented relationships with those from different cultures and welcome them more easily (Rockstuhl, Seiler, Ang, Van Dyne \& Annen, 2011). In this regard, the knowledge of teachers about the differences at schools where students from different cultures study together, their efforts to establish effective communication with all students and their development of positive attitudes and behaviors towards them can be classified within the scope of cultural intelligence. As stated by Triandis (2006), cultural intelligence is an important element for the development of interpersonal relationships within the institutions of cultural diversity. Therefore, teachers are expected to have high levels of cultural intelligence at schools, which are among the culturally diverse institutions, to be successful in interacting with refugee students and to ensure their integration into education.

Cultural intelligence comprises a multidimensional structure with metacognitive, cognitive, motivational and behavioral dimensions (Earley \& Ang, 2003; Earley, Ang \& Tan 2006). The metacognitive aspect of cultural intelligence reflects the mental processes that the individuals use to acquire and understand cultural information. The cognitive aspect indicates the norms and practices achieved through education and daily experiences from different cultures (Ang \& Van Dyne, 2008; Ang, Van Dyne \& Tan, 2011) and includes being aware of the basic frameworks of cultural values and having information about social, legal and economic systems of different cultures (Petrović, 2011). Motivation, another dimension of cultural intelligence, is about the willingness of individuals to communicate with those of different cultures and to learn from them (Ang \& Van Dyne, 2008; Ng, Dyne \& Ang, 2009). Behavioral dimension is characterized to be the ability of individuals to adjust verbal (tone of voice, speaking speed) and nonverbal (gesture, mimic) behaviors in their communication with individuals of different cultures based on the context (Ang, Van Dyne \& Koh, 2006). When the sub-dimensions of cultural intelligence are employed to the context of education, teachers' having information about the cultural values, norms, economic and legal systems of refugee students is related to the sub-dimensions of metacognitive and cognitive aspects whilst their attempts to make the students eager to learn and to establish a quality communication with them, and the attitudes and behaviors in this vein are related to the sub-dimensions of motivational and behavioral aspects. 
As an essential constituent for the education of refugee students, teachers need to support the social, emotional and academic development of the students (Pumariega, Rothe \& Pumariega, 2005) and to create an atmosphere for the students where they can express themselves comfortably and communicate effectively with their classmates via providing their active participation (Reyes, Brackett, Rivers, White, \& Salovey, 2012). In this context, teachers' developing positive attitudes towards students and supporting them emotionally are suggested to be critical in increasing the students' abilities, social skills and adaptation to school and environment (Hyson, 2004; Mashburn et al., 2008). Therefore, it is believed that cultural intelligence which can be taught and developed (Macnab \& Worthley, 2012; Triandis, 2006) may positively impact the attitudes of teachers toward refugee students.

The success of educational activities is directly proportional to teachers' encouraging the students to learn by meeting their requirements (Caruth, 2018). For this purpose, primary school teachers should be aware of the cultural differences of the students within the classroom, be able to manage the cultural differences viably, and minimize the orientation problems of the students. Thereupon, it is highly important to provide teachers with an atmosphere where they can improve their level of cultural intelligence in line with the results obtained through determining the relationship between the cultural intelligence levels of teachers with their attitudes to students. In this regard, it was aimed to investigate the relationship between the cultural intelligence levels of teachers working at primary schools and their attitudes towards refugee students. The answers to the following questions were sought in line with the main purpose of the study.

(1) What are the cultural intelligence levels of teachers and their attitudes towards refugee students?

(2) Are there significant relationships between cultural intelligence and its subdimensions (metacognitive, cognitive, motivational, behavioral) and the attitudes towards refugee students?

(3) Is cultural intelligence a significant predictor of the attitudes towards refugee students?

(4) Are the sub-dimensions of cultural intelligence (metacognitive, cognitive, motivational, behavioral) significant predictors of the attitudes towards refugee students?

\section{Methodology}

\section{The Research Model}

The present study examined the relationship between cultural intelligence and the attitudes towards refugee students was designed with the correlational survey model which aims to identify the existence and direction of the relationship between two or more variables (Karasar, 2015). The research in this model begins with the determination of the link between the variables and then the cause-effect relationship between the variables is uncovered.

\section{The Universe of the Study and Sampling Procedure}

The universe of the study included primary school teachers working at schools, at least $10 \%$ of whose size was composed of Syrian (refugee) students in Nizip district of Gaziantep in the academic year of 2019-2020. The research sample consisted of 386 primary school teachers who were selected via simple random sampling technique among the universe. The 
scales were distributed to approximately 500 teachers, considering the rate of return. After eliminating incorrect and incomplete forms, $77.2 \%$ of them were assumed to be valid and 386 scales were analysed. Based on the computations, it was decided that the sample size was satisfactory on $95 \%$ confidence interval and $\alpha=.05$ level of significance (Özdamar, 2003; Field, 2009). Information on the demographic characteristics of the participants is presented in Table 1.

Table 1. Demographic characteristics of the participants

\begin{tabular}{llrc}
\hline Demographic Characteristics & & n & \% \\
\hline Gender & Female & 226 & 58.5 \\
& Male & 160 & 41.5 \\
\hline Marital Status & Married & 268 & 69.4 \\
& Single & 118 & 30.6 \\
\hline Age & $21-30$ years & 164 & 42.5 \\
& $31-40$ years & 145 & 37.6 \\
& 41 - or more years & 77 & 19.9 \\
\hline Professional Seniority & $1-5$ years & 133 & 34.5 \\
& 6-10 years & 79 & 20.5 \\
& $11-15$ years & 75 & 19.4 \\
& $16-20$ years & 47 & 12.1 \\
& 21 - or more years & 52 & 13.5 \\
\hline Educational Level & Bachelor & 372 & 96.4 \\
& Postgraduate & 14 & 3.6 \\
\hline
\end{tabular}

According to Table 1 teachers, 58.5\% ( $\mathrm{n}=226)$ were female, $41.5 \%(\mathrm{n}=160)$ were male; $69.4 \%(n=268)$ were married, $30.6 \%(n=118)$ were single. By the groups of age, $42.5 \%$ of them $(n=164)$ were between $21-30$ years, $37.6 \%(n=145)$ were between $31-40$ years, $(n=77)$ $19.9 \%$ were 41 or more years. In terms of professional seniority, $34.5 \%(n=133)$ of the respondents had 1-5 years; $20.5 \%(n=79)$ had $6-10$ years; $19.4 \%(n=75)$ had $11-15 ; 12.2 \%$ $(n=47)$ had $16-20$ years and $13.5 \%(n=52)$ had 21 or more years of seniority. While the ratio of teachers with bachelor's degree was $96.4 \%(n=372)$, the ratio of those with postgraduate degree was $3.6 \%(n=14)$.

\section{Data Collection Instruments}

The data of the study were collected through "Demographic Questions", "Cultural Intelligence Scale" and "Refugee Student Attitude Scale". Cultural Intelligence Scale is a 5point Likert type instrument with the options of "1- Strongly disagree", "2- Disagree", "3Moderately agree", "4- Agree" and "5- Strongly agree". On the other hand, Refugee Student Attitude Scale is a 4-point Likert type instrument with "1- Don't agree at all", "2- Moderately agree, "3- Mostly agree" and "4- Totally agree".

Cultural Intelligence Scale: The Cultural Intelligence Scale (CQS) developed by Ang et al. (2007) adapted to Turkish by Illhan and Çetin (2014) with its psychometric tests. The scale consists of 20 items and 4 sub-dimensions (metacognitive, cognitive, motivational, behavioural). The total variance explained by the four dimensions was $52.66 \%$, and Cronbach's Alpha internal consistency coefficient for the overall scale was found to be .85. It was affirmed that the scale can be evaluated in terms of the sub-dimensions or based on the total score to be obtained from the sum of the sub-dimensions. Reliability and validity studies of the scale were also performed for the present study. Cronbach's Alpha internal consistency coefficient was estimated to be .94 for the overall scale. As the original scale was developed on the basis of theoretical foundations and the dimensions related to the items that appear, no 
exploratory factor analysis was performed within the scope of this study. The construct validity of the scale was tested via confirmatory factor analysis (CFA). During the analysis stage, so as to improve the model fit, the item numbered CQ16 was removed from the dataset due to producing higher chi-square value as being associated with different sub-dimensions. As a result of the modifications, covariances were created between the error terms of CQ7 and CQ8 along with CQ14 and CQ15 based on theory. It has been observed that the researchers usually reported the estimates of $\chi^{2}$ (Chi-Square), $\chi^{2} / \mathrm{df}$ (The Ratio of Chi-Square to Degree of Freedom), GFI (Goodness Fit Index), NFI (Normed Fit Index), TLI (The Tucker-Lewis Index), CFI (Comparative Fit Index), RMSEA (The Root Mean Square Error of Approximation) and SRMR (Standardized Root Mean Square Residual) in CFA (Meydan \& Şeşen, 2015). Thus, it was decided to report the aforementioned estimates for the present study. As a result of CFA, model fit indices were determined to be $\chi^{2}=400.307, \chi^{2} / \mathrm{df}=2.780$, $\mathrm{p}=0.00, \mathrm{GFI}=0.903$, NFI=0.921, TLI=0.938, CFI=0.948, RMSEA=0.068 and SRMR=0.052. It was concluded that the estimates were acceptable (Byrne \& Campbell, 1999; Hu \& Bentler, 1999; Kline, 2011), the scale was confirmed for the research sample, and thus it was structurally appropriate.

Refugee Student Attitude Scale: The scale developed by Sağlam and Kanbur (2017) consists of three dimensions (communication, adaptation, and efficiency) and 24 items. The total variance explained by the three dimensions was estimated to be $53.61 \%$, and Cronbach's Alpha internal consistency coefficient was found to be .91. It was declared that the scale can be evaluated on the basis of sub-dimensions or total score. The reliability and validity studies of the scale were performed for the current study. The Cronbach's Alpha internal consistency coefficient was estimated to be .88 for the overall scale. As the scale was developed in line with the theoretical foundations and was previously administered to the sample of teachers, no exploratory factor analysis was performed. As a result of the CFA conducted to test the construct validity of the scale, the item numbered RSA10 with low performing factor load (.29) was removed from the data set. The items numbered RSA16 and RSA21 were also eliminated as they were associated with different sub-dimensions which caused higher chisquare values. There were different results for the specified items (e.g. the items of 16, 21) in another study as well (Terzi, Göçen \& Altun, 2019), which could stem from different conceptualization of the items by different sample groups. As a result of the modifications to improve the model fit, covariances were created based on theory between the error terms of RSA1 and RSA2, RSA8 and RSA9 along with RSA17 and RSA18 which placed under similar dimensions. According to the CFA results, model fit indices were at acceptable levels; $\chi^{2}=364.603, \quad \chi^{2} / \mathrm{df}=2.237, \quad \mathrm{p}=0.00, \quad \mathrm{GFI}=0.913, \quad \mathrm{NFI}=0.887, \quad \mathrm{TLI}=0.923, \quad$ CFI $=0.934$, RMSEA=0.057 and SRMR=0.033 (Byrne \& Campbell, 1999; Hu \& Bentler, 1999; Kline, 2011). The results proved that the scale was confirmed for the research sample and it was structurally viable.

\section{Data Analysis}

SPSS 22.0 and AMOS 23.0 software packages were used to analyse the data. Stepwise multiple regression analysis was conducted to identify the role of cultural intelligence in predicting the attitudes towards refugee students. Before analysing, the assumptions of outliers, linearity and normality, multicollinearity, and covariance were tested. Regarding multicollinearity, it was revealed that the binary correlations between the variables were less than .90 , the VIF estimates were less than 10 and the tolerance limits were greater than .10. All these indicate the absence of multicollinearity (Büyüköztürk, 2003). In addition, it was established that the values of the independent variable and the subset of the values of the 
dependent variable were equal (covariance) for the dataset. Based on the estimation of the " $\mathrm{z}$ " scores of each scale item in dataset, 14 numbers of outliers disrupting the distribution of data were detected and cleared as they were greater than -3 or +3 (Çokluk, Şekercioğlu \& Büyüköztürk, 2012). Afterwards, skewness and kurtosis were checked and it was observed that they varied between -1.5 and +1.5 . All these implied that the research data were distributed normally (Tabachnick \& Fidell, 2013). In data analysis, SPSS 22.0 was used to find descriptive statistics such as mean score, standard deviation and standard error, and to estimate Pearson Correlation Coefficient, and AMOS 23.0 was used in CFA to test the construct validity. Internal consistency coefficients (Cronbach's Alpha) were computed within the scope of reliability studies. The direction and level of the relationship between the variables were determined through the correlation coefficient. The independent variables' (cultural intelligence and its sub-dimensions) level of predicting the dependent one (the attitudes towards refugee students) was discovered through performing stepwise multiple regression analysis.

\section{Findings}

\section{Descriptive Statistics for the Variables}

Descriptive statistics such as mean score, standard deviation and standard error for the variables were presented in Table 2.

Table 2. Mean scores, standard deviation, and standard error for cultural intelligence and the attitudes towards refugee students

\begin{tabular}{lccc}
\hline Variables & $\bar{X}$ & SD & Std. Error \\
\hline 1. Cultural Intelligence & 3.38 & .65 & .03 \\
2. The Attitudes Towards Refugee Students & 3.08 & .43 & .02 \\
\hline
\end{tabular}

It should be taken into account for the assessment of mean scores in Table 2 that Cultural Intelligence Scale is a 5-point Likert type instrument while Refugee Student Attitude Scale is a 4-point Likert type instrument. Accordingly, the cultural intelligence perceptions of teachers were at moderate level $(\overline{\mathrm{X}}=3.38)$ and their attitudes towards refugee students were relatively high $(\bar{X}=3.08)$.

\section{The Correlation Coefficients of the Variables}

Correlation coefficients indicating the direction and level of the relationship between the variables were given in Table 3.

Table 3. Correlation coefficients for the relationship between cultural intelligence and its subdimensions with the attitudes towards refugee students

\begin{tabular}{lcccccc}
\hline Variables & $\mathbf{1}$ & $\mathbf{2}$ & $\mathbf{3}$ & $\mathbf{4}$ & $\mathbf{5}$ & $\mathbf{6}$ \\
\hline 1. Metacognitive CQ & 1 & & & & & \\
2. Cognitive CQ & $.475^{* *}$ & 1 & & & & \\
3. Motivational CQ & $.507^{* *}$ & $.664^{* *}$ & 1 & & & \\
4. Behavioural CQ & $.485^{* *}$ & $.545^{* *}$ & $.648^{* *}$ & 1 & & \\
5. Cultural Intelligence & $.703^{* *}$ & $.861^{* *}$ & $.882^{* *}$ & $.802^{* *}$ & 1 & \\
6. The Attitudes Towards Refugee Students & $.480^{* *}$ & $.437^{* *}$ & $.498^{* *}$ & $.420^{* *}$ & $.555^{* *}$ & 1 \\
\hline
\end{tabular}

$* \mathrm{p}<.05, * * \mathrm{p}<.01, * * * \mathrm{p}<.001$ 
The correlation coefficients in Table 3 implied that there was a positive $(\mathrm{r}=.555, \mathrm{p}<.01)$ relationship at moderate level between cultural intelligence and the attitudes towards refugee students. In addition, the relationships between the attitudes towards refugee students and the metacognitive $(\mathrm{r}=.480, \mathrm{p}<.01)$, cognitive $(\mathrm{r}=.437, \mathrm{p}<.01)$, motivational $(\mathrm{r}=.498, \mathrm{p}<.01)$ and behavioural $(\mathrm{r}=.420, \mathrm{p}<.01)$ sub-dimensions of cultural intelligence were also found to be positive and moderate. In other words, the rise in the cultural intelligence level of teachers enables them to develop positive attitudes towards refugee students while the low level of cultural intelligence may result in developing negative attitudes towards refugee students.

Stepwise multiple regression analyses were performed to provide stronger evidence for the obtained findings. Thus, it was aimed to determine whether cultural intelligence and its subdimensions significantly predicted the attitudes towards refugee students and it was also intended to identify the level of predictor effect if it was the case.

\section{Predicting the Attitudes towards Refugee Students through Cultural Intelligence}

The results of stepwise multiple regression analysis for predicting the attitudes towards refugee students through cultural intelligence were submitted in Table 4.

Table 4. The results of regression analysis to predict the attitudes towards refugee students through cultural intelligence

\begin{tabular}{|c|c|c|c|c|c|c|}
\hline Model & Predictor variables & B & Std. Error & $\boldsymbol{\beta}$ & $\mathbf{t}$ & $\mathbf{p}$ \\
\hline \multirow{4}{*}{ 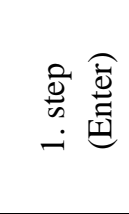 } & (constant) & 3.037 & .063 & & 48.413 & .000 \\
\hline & Gender_dummy & .138 & .045 & .160 & 3.048 & .002 \\
\hline & Age & .028 & .029 & .049 & .941 & .347 \\
\hline & Number of refugee students & -.006 & .003 & -.092 & -1.828 & .068 \\
\hline \multirow{5}{*}{ 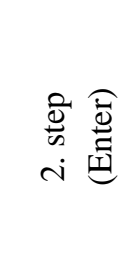 } & (constant) & 1.809 & .108 & & 16.775 & .000 \\
\hline & Gender_dummy & .035 & .039 & .040 & .903 & .367 \\
\hline & Age & .057 & .025 & .102 & 2.339 & .020 \\
\hline & Number of refugee students & -.007 & .003 & -.109 & -2.597 & .010 \\
\hline & Cultural Intelligence & .363 & .028 & .557 & 13.024 & .000 \\
\hline
\end{tabular}

Predicted variable: The Attitudes Towards Refugee Students

$\mathrm{R}=.579, \mathrm{R}^{2}=.335$, adj. $\mathrm{R}^{2}=.328, \mathrm{~F}_{(4,381)}=47.940, * \mathrm{p}<.05, * * \mathrm{p}<.01, * * * \mathrm{p}<.001$

As clear in the results of stepwise multiple regression analysis in Table 4, the variables of gender_dummy $(0=$ female, $1=$ male $)$, age and the number of refugee students in classroom were controlled in the first step with the assumption that they may alter the analysis results. In the second step, cultural intelligence was added to the model. As a result of the analysis, it was revealed that age $\left(\beta=.102^{*}, \mathrm{t}=2.339, \mathrm{p}<.05\right)$, number of refugee students $\left(\beta=-.109^{*}, \mathrm{t}=-\right.$ $2.597, \mathrm{p}<.05)$ and cultural intelligence $\left(\beta=.557^{* * *}, \mathrm{t}=13.024, \mathrm{p}<.001\right)$ was significant predictors of the attitudes towards refugee students. Each unit of increase in cultural intelligence created .557 unit of growth in the attitudes towards refugee students. Age and the number of refugee students were controlled, cultural intelligence explained $32.8 \%$ (adj. $\left.\mathrm{R}^{2}=.328 ; \mathrm{p}<.05\right)$ of teachers' attitudes towards refugee students. Increased cultural intelligence levels of teachers enabled them to develop more positive attitudes towards refugee students. 


\section{Predicting the Attitudes towards Refugee Students through the Sub-dimensions of Cultural Intelligence}

The results of stepwise multiple regression analysis for predicting the attitudes towards refugee students through the sub-dimensions of cultural intelligence (metacognitive, cognitive, motivational and behavioural CQ) were presented in Table 5.

Table 5. The results of regression analysis to predict the attitudes towards refugee students through the sub-dimensions of cultural intelligence

\begin{tabular}{|c|c|c|c|c|c|c|}
\hline Model & Predictor variables & B & Std. Error & $\boldsymbol{\beta}$ & $\mathbf{t}$ & $\mathbf{p}$ \\
\hline \multirow{4}{*}{ 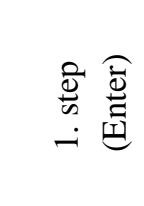 } & (constant) & 3.037 & .063 & & 48.413 & .000 \\
\hline & Gender_dummy & .138 & .045 & .160 & 3.048 & .002 \\
\hline & Age & .028 & .029 & .049 & .941 & .347 \\
\hline & Number of refugee students & -.006 & .003 & -.092 & -1.828 & .068 \\
\hline \multirow{8}{*}{ 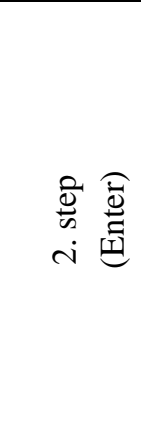 } & (constant) & 1.659 & .121 & & 13.703 & .000 \\
\hline & Gender_dummy & .029 & .038 & .034 & .758 & .449 \\
\hline & Age & .055 & .024 & .098 & 2.250 & .025 \\
\hline & Number of refugee students & -.007 & .003 & -.107 & -2.570 & .011 \\
\hline & Metacognitive CQ & .165 & .032 & .262 & 5.206 & .000 \\
\hline & Cognitive CQ & .063 & .031 & .117 & 2.030 & .043 \\
\hline & Motivational CQ & .118 & .031 & .240 & 3.775 & .000 \\
\hline & Behavioural CQ & .040 & .030 & .077 & 1.347 & .179 \\
\hline
\end{tabular}

Predicted variable: The Attitudes Towards Refugee Students

$\mathrm{R}=.594, \mathrm{R}^{2}=.352$, adj. $\mathrm{R}^{2}=.340, \mathrm{~F}_{(7,378)}=29.372, * \mathrm{p}<.05, * * \mathrm{p}<.01, * * * \mathrm{p}<.001$

As seen in stepwise multiple regression analysis in Table 5, the sub-dimensions of cultural intelligence were added to the model in the second step after controlling the variables of gender_dummy $(0=$ female, $1=$ male $)$, age and the number of refugee students in the first step. As a result of the analysis, it was determined that the attitudes towards refugee students was significantly predicted by age $\left(\beta=.098^{*}, t=2.250, p<.05\right)$, number of refugee students $(\beta=-$ $\left..107^{*}, \mathrm{t}=-2.570, \mathrm{p}<.05\right)$, metacognitive $\left(\beta=.262^{* * *}, \mathrm{t}=5.206, \mathrm{p}<.001\right)$, cognitive $\left(\beta=.117^{*}, \mathrm{t}=\right.$ $2.030, \mathrm{p}<.05)$ and motivational $\left(\beta=.240^{* *}, \mathrm{t}=3.775, \mathrm{p}<.01\right)$ sub-dimensions of cultural intelligence. It was understood that the behavioural sub-dimension of cultural intelligence was not a significant predictor for the attitudes towards refugee students $(\beta=.077, \mathrm{t}=1.347, \mathrm{p}>.05)$. A one-unit increase in age generated .098 unit of growth in the attitudes towards refugee students. A one-unit increase in number of refugee students resulted in a decrease of .107 unit in the attitudes towards refugee students. A one-unit increase in the metacognitive subdimension generated .262 unit of growth in the attitudes towards refugee students. A one-unit increase in the cognitive sub-dimension resulted in a growth of .117 unit in the attitudes towards refugee students. A one-unit increase in the sub-dimension of motivation yielded .240 unit of growth in the attitudes towards refugee students. The $34.0 \%$ of the attitudes towards refugee students was explained by the metacognitive, cognitive and motivational subdimensions of cultural intelligence $\left({ }_{\text {adj }} \mathrm{R}^{2}=.340 ; \mathrm{p}<.05\right)$. All the findings indicated that the increase in the metacognitive, cognitive and motivational sub-dimensions of cultural intelligence contributed to more positive attitudes of teachers towards refugee students. 


\section{Discussion and Conclusion}

The respondents' levels of perception were initially unveiled in the present study examining the relationship between the cultural intelligence levels of primary school teachers and their attitudes towards refugee students. In this regard, mean scores and standard deviation were estimated. It was concluded that cultural intelligence perception of teachers was at moderate level and their attitudes towards refugee students were relatively high. In other words, teachers implied that they had knowledge about the characteristics of students with different cultural backgrounds in their classroom, they attempted to communicate positively with them and they sought to exhibit positive attitudes and behaviours. In support of the research findings, Rengi and Polat (2014) ascertained in their study that the primary school teachers had positive feelings and were prone to exhibit sensitive behaviours and attitudes towards the students with cultural differences. Similarly, Karatas (2015) uncovered that teachers' attitudes towards the students with different cultural backgrounds were at higher levels, they welcomed education in culturally diverse classes, and they paid attention to communication. Therefore, it is possible to allege that the skills of primary school teachers implying cultural intelligence such as positive communication, organizing learning environments, motivating, problem-solving and orientating the students from different cultures were moderate and their attitudes towards refugee students were relatively high based on the research results.

According to another finding of the study, there was a positive and significant relationship between the cultural intelligence levels of teachers and their attitudes towards refugee students. In other words, the rise in the cultural intelligence level of teachers enabled them to develop positive attitudes towards refugee students while the low level of cultural intelligence resulted in developing negative attitudes towards refugee students. Topkaya and Akdağ (2016) argued that the coexistence of teachers with refugee students allowed them to recognize different cultures and empathize with students. Bele and Hebalkar (2019) suggested that teachers should have high level of cultural intelligence in order to understand the students better and provide effective training. This the reason why, the individuals with high level of cultural intelligence establish trust-oriented relationships with those from different cultures and welcome them more easily (Rockstuhl et al., 2011). In this direction, the knowledge of teachers about the differences at schools where students from different cultures study together, their efforts to establish effective communication with all students, their development of positive attitudes and behaviors towards students can be listed within the framework of cultural intelligence.

After determining the relationship between the variables in the correlation analysis, stepwise multiple regression analysis was performed to identify the predictor effect of cultural intelligence on the attitudes towards refugee students. The gender, age and the number of refugee students in their classroom were added as control variables for the initial step of the first model with the assumption that they may alter the analysis results. With the addition of cultural intelligence into the model in the second step, it was revealed that cultural intelligence significantly predicted the attitudes towards refugee students. In other words, when gender, age and the number of refugee students were controlled, the rise in the cultural intelligence levels of teachers improved their positive attitudes towards refugee students. Pumariega, Rothe and Pumariega (2005) emphasized that teachers should support the social, emotional and academic development of refugee students while Reyes et al. (2012) indicated that teachers should create a positive communication atmosphere among students through actively involving them in the classroom. In addition, it was noted that teachers' developing a 
positive attitude towards students and providing emotional support were critical in increasing the abilities and social skills of students and in their adaptation to school and environment (Hyson, 2004; Mashburn et al., 2008). Therefore, it can be argued that cultural intelligence which can be taught and developed (Macnab \& Worthley, 2012; Triandis, 2006) can positively affect teachers' attitudes towards refugee students. In light of these, it was observed that the research finding that teachers' high level of cultural intelligence positively predicted their attitudes towards refugee students in their classrooms was supported by the relevant literature.

It was dwelled upon whether the sub-dimensions of cultural intelligence predicted the attitudes towards refugee students in the second model of stepwise regression analysis. In the first step, gender, age and the number of refugee students in classroom were controlled, and the attitudes towards refugee students was included in the second step of the model. As a result of the analysis, it was determined that metacognitive, cognitive and motivational subdimensions of cultural intelligence positively and significantly predicted the attitudes towards refugee students except for the behavioral sub-dimension. The metacognitive sub-dimension of cultural intelligence includes mental processes used to obtain and understand cultural information (Earley \& Ang, 2003; Earley, Ang \& Tan 2006). In this regard, it can be alleged that teachers' attempts to obtain information about the culture of refugee students would positively influence their attitudes. The cognitive sub-dimension covering the norms and practices obtained through education and daily experiences from varying cultures (Ang \& Van Dyne, 2008; Ang, Van Dyne \& Tan, 2011) can also be considered a significant factor on the attitudes towards refugee students. It is hoped that the knowledge of teachers about the culture of refugee students would enable them to get closely acquainted and would influence their attitudes positively. The number of researchers cited that the teachers' knowledge of different cultures may positively affect their attitudes towards refugee students in that teachers should recognize their students from many aspects in a world of cultural diversity and globalization (Petrović \& Zlatković, 2009), cultural intelligence is an important factor in the education of students with different cultures at schools (Ramis \& Krastina, 2010) and the schools provide an opportunity with refugee children to carry themselves into the future and to integrate with society (Rousseau \& Guzder, 2008). Motivation which is related to the willingness to communicate with individuals from different cultures and to learn from them (Ang \& Van Dyne, 2008; Ng, Dyne \& Ang, 2009) also positively influences the attitudes towards refugee students. In light of these, it can be suggested that teachers' attempts to get to know students from different cultures in the classroom and to establish positive communication with them would positively affect their attitudes towards refugee students.

It is possible to offer various recommendations for practitioners and researchers based on the findings obtained from the study. As cultural intelligence includes educable and improvable forms of behavior, it can be suggested to support the students with different cultures socially, cognitively and behaviorally by introducing practices (in-service trainings, seminars, implementations or case-based developmental activities etc.) that would improve teachers' level of cultural intelligence. The activities ensuring those students to communicate positively with both their teachers and their classmates can be organized with a view to developing the positive attitudes towards refugee students and to enabling their adaptation and recognition within the school. Aside from cultural intelligence, studies can be conducted with the variables such as self-efficacy, personality traits, emotional intelligence, diversity management, and etc. which may influence teachers' attitudes towards refugee students. The present study was limited to primary schools in Nizip district of Gaziantep province. Thus, the similarities and differences between the results of the studies to be conducted in different 
cities and samples can be revealed. In future research, qualitative and mixed method research can be carried out for the in-depth examination of the relationship between the variables.

\section{References}

Akşit, G., Bozok, M., \& Bozok, N. (2015). Zorunlu göç, sorunlu karşılaşmalar: Hisar köyü, Nevşehir'deki Suriyeli göçmenler örneği [Forced migration, problematic encounters: Hisar village, an example of Syrian immigrants in Nevşehir]. Maltepe University Faculty of Science and Literature Journal, 1(2), 92-116.

Ang, S., \& Van Dyne, L., (2008). Conceptualization of cultural intelligence: Definition, distinctiveness, and nomological network. In S. Ang, \& L. Van Dyne, (Ed.), Handbook on cultural intelligence: Theory, measurement and applications (pp. 3-15). Armonk, NY: M.E. Sharpe.

Ang, S., Van Dyne, L., Koh, C., Ng, K. Y., Templer, K. J., Tay, C., \& Chandrasekar, N. A. (2007). Cultural intelligence: Its measurement and effects on cultural judgment and decision making, cultural adaptation and task performance. Management and Organization Review, 3(3), 335-371.

Ang, S., Van Dyne, L., \& Koh, C. (2006). Personality correlates of the four factor model of cultural intelligence. Group \& Organization Management, 31(1), 100-123.

Ang, S., Van Dyne, L. \& Tan, M. L. (2011). Cultural intelligence. In. R. J. Sternberg \& S. B. Kaufman (Ed.), Cambridge handbook on intelligence (pp. 582-602). New York: Cambridge Press.

Arastaman, G. (2018). A study of validity and reliability evidences of cultural intelligence scale on Turkish academics. Journal of Higher Education, 8(1), 1-8. https://doi.org/ 10.2399/yod.17.025

Aydin, H., \& Kaya, Y. (2017). The educational needs of and barriers faced by Syrian refugee students in Turkey: A qualitative case study. Intercultural Education, 28(5), 456-473.

Bele, M. R., \& Hebalkar, R. (2019). Perception of teachers about cultural intelligence: An essential skill in global economy. ANVESHAK-International Journal of Management, 8(1), 84-104. https://doi.org/10.15410/aijm/2019/v8i1/140607

Block, K., Cross, S., Riggs, E., \& Gibbs, L. (2014). Supporting schools to create an inclusive environment for refugee students. International Journal of Inclusive Education, 18(12), 1337-1355.

Börü, N., \& Boyac1, A. (2016). Immigrant students' problems in education - instruction processes (An example of the province of Eskişehir). Electronic Turkish Studies, 11(14), 123-158.

Büyüköztürk, Ş. (2003). Sosyal bilimler için veri analizi el kitabı [Data analysis handbook for social sciences statistics]. Ankara: PegemA Publishing.

Byrne, B. M., \& Campbell, T. L. (1999). Cross-cultural comparisons and the presumption of equivalent measurement and theoretical structure: A look beneath the surface. Journal of Cross-Cultural Psychology, 30(5), 555-574.

Caruth, G. D. (2018). Student engagement, retention, and motivation: Assessing academic success in today's college students. Participatory Educational Research, 5(1), 17-30. http://eoi.citefactor.org/10.11203/per.18.4.5.1

Chiu, M. M., Pong, S. L., Mori, I., \& Chow, B. W. Y. (2012). Immigrant students' emotional and cognitive engagement at school: A multilevel analysis of students in 41 countries. Journal of Youth and Adolescence, 41(11), 1409-1425. https://doi.org/10.1007/s10964-012-9763-x

Çelik, Ç., \& İçduygu, A. (2019). Schools and refugee children: the case of Syrians in Turkey. International Migration, 57(2), 253-267. https://doi.org/10.1111/imig.12488

Çokluk, Ö., Şekercioğlu, G., \& Büyüköztürk, Ş. (2012). Sosyal bilimler için çok değişkenli SPSS ve LISREL uygulamalart [Multivariate SPSS and LISREL applications for social sciences]. Ankara: PegemA Publishing. 
Earley, P. C., \& Ang, S. (2003). Cultural intelligence: Individual interactions across cultures. Stanford C. A: Stanford University Press.

Earley, P. C., Ang, S., \& Tan, J. S. (2006). CQ: Developing cultural intelligence at work. Palo Alto, C.A: Stanford University Press.

Field, A. (2009). Discovering statistics using SPSS. Dubai: Oriental Press.

Hu, L., \& Bentler, P. M. (1999). Cut off criteria for fit indexes in covariance structure analysis: Conventional criteria versus new alternatives. Structural Equation Modelling: A Multidisciplinary Journal, 6(1), 1-55. https://doi.org/10.1080/10705519909540118

Hyson, M. (2004). The emotional development of young children: Building an emotion-centered curriculum. New York: Teachers College Press.

İlhan, M., \& Çetin, B. (2014). Validity and reliability study of the Turkish version of the cultural intelligence scale. Hacettepe University Journal of Education, 29(2), 94-114.

Jafari, K. K., Tonga, N., \& Kışla, H. (2018). Practice and opinions of the teachers who work at the classes have Syrian students. Academy Journal of Educational Sciences, 2(2), 134-146. https://doi.org/10.31805/acjes.479232

Karasar, N. (2015). Bilimsel araştırma yöntemleri (28. bas.) [Scientific research methods (28th ed.)]. Ankara: Nobel Academy Publishing.

Karatas, S. (2015). Teachers' views on multicultural education: Sample of Antalya. The Anthropologist, 19(2), 373-380. https://doi.org/10.1080/09720073.2015.11891670

Keung, E. K., \& Rockinson-Szapkiw, A. J. (2013). The relationship between transformational leadership and cultural intelligence. Journal of Educational Administration, 51(6), 836854. https://doi.org/10.1108/JEA-04-2012-0049

Kılcan, B., Çepni, O., \& Kılınç, A. Ç. (2017). Development of the attitude towards refugee students scale. Journal of Human Sciences, 14(2), 1045-1057. https://doi.org/10.14687/jhs.v14i2.4324

Kline, R. B. (2011). Principles and practice of structural equation modeling. New York, NY: Guilford.

Ladson-Billings, G. (1995). Toward a theory of culturally relevant pedagogy. American Educational Research Journal, 32(3), 465-491.

MacNab, B. R., \& Worthley, R. (2012). Individual characteristics as predictors of cultural intelligence development: The relevance of self-efficacy. International Journal of Intercultural Relations, 36(1), 62-71. https://doi.org/10.1016/j.ijintrel.2010.12.001

Mahasneh, A. M., Gazo, A. M., \& Al-Adamat, O. A. (2019). Cultural intelligence of the Jordan teachers and university students from the Hashemite University: Comparative study. European Journal of Contemporary Education, 8(2), 303-314. https://doi.org/10.13187/ejced.2019.2.303

Mashburn, A. J., Pianta, R. C., Hamre, B. K., Downer, J. T., Barbarin, O. A., Bryant, D., ... \& Howes, C. (2008). Measures of classroom quality in prekindergarten and children's development of academic, language, and social skills. Child Development, 79(3), 732-749. https://doi.org/10.1111/j.1467-8624.2008.01154.x

Meydan, C. H., \& Şeşen, H. (2015). Yapısal eşitlik modellemesi AMOS uygulamaları [Structural equation modeling AMOS applications]. Ankara: Detay Publishing.

Ng, K. Y., Van Dyne, L., \& Ang, S. (2009). From experience to experiential learning: Cultural intelligence as a learning capability for global leader development. Academy of Management Learning \& Education, 8(4), 511-526.

Özdamar, K. (2003). Modern bilimsel araştırma yöntemleri [Modern scientific research methods]. Eskişehir: Kaan Bookstore.

Petrović, D. S. (2011). How do teachers perceive their cultural intelligence?. Procedia-Social and Behavioral Sciences, 11, 276-280. https://doi.org/10.1016/j.sbspro.2011.01.076

Petrović, D., \& Zlatković, B. (2009). Intercultural sensitivity of future primary school teachers. Comparative Education, Teacher Training, Education Policy and Social Inclusion, 121-128. 
Pumariega, A. J., Rothe, E., \& Pumariega, J. B. (2005). Mental health of immigrants and refugees. Community Mental Health Journal, 41(5), 581-597.

Ramis, M., \& Krastina, L. (2010). Cultural intelligence in the school. Revista de Psicodidáctica, 15(2), 239-252.

Rengi, Ö., \& Polat, S. (2014). Sınıf öğretmenlerinin kültürel farklılık algıları ve kültürlerarası duyarlıliklar1 [Primary teachers' perception of cultural diversity and intercultural sensitivity]. Journal of World of Turks, 6(3), 135-156.

Reyes, M. R., Brackett, M. A., Rivers, S. E., White, M., \& Salovey, P. (2012). Classroom emotional climate, student engagement, and academic achievement. Journal of Educational Psychology, 104(3), 700- 712. https://doi.org/10.1037/a0027268

Rockstuhl, T., Seiler, S., Ang, S., Van Dyne, L., \& Annen, H. (2011). Beyond general intelligence (IQ) and emotional intelligence (EQ): The role of cultural intelligence (CQ) on cross border leadership effectiveness in a globalized world. Journal of Social Issues, 67(4), 825-840. https://doi.org/10.1111/j.1540-4560.2011.01730.x

Rousseau, C., \& Guzder, J. (2008). School-based prevention programs for refugee children. Child Adolesce Psychiatric Clinics of North America, 17(3), 533-549. https://doi.org/10.1016/j.chc.2008.02.002

Sağlam, H. İ., \& Kanbur, N. İ. (2017). Investigation attitudes towards refugee Students of class teachers' in terms of several variables. Sakarya University Journal of Education, 7(2), 310-323. https://doi.org/10.19126/suje.335877

Tabachnick, B. G., \& Fidell, L. S. (2013). Using multivariate statistics (6 $6_{\text {th }}$ ed.). Pearson, Boston.

Taylor, S., \& Sidhu, R. K. (2012). Supporting refugee students in schools: What constitutes inclusive education?. International Journal of Inclusive Education, 16(1), 39-56. https://doi.org/10.1080/13603110903560085

Terzi, R., Göçen, A., \& Altun, B. (2019). Mülteci öğrencilere yönelik tutumların çeşitli değişkenlere göre incelenmesi. Revize edilmiş Mülteci Öğrencilere Yönelik Tutum Ölçeği [Investigating attitudes towards refugee students based on several variables: Revised version of Refugee Student Attitude Scale]. Sakarya University Journal of Education, 9(3), 476-494. https://doi.org/10.19126/suje.526197

Thomas, D.C. (2006). Domain and development of cultural intelligence: The importance of mindfulness. Group \& Organization Management, 31(1), 78-99. https://doi.org/10.1177/1059601105275266

Topkaya, Y., \& Akdağ, H. (2016). Prospective social studies teachers' views about Syrian defector (Kilis 7 Aralı University Sample). Cankiri Karatekin University Journal of Institute of Social Sciences, 7(1), 767-786.

Triandis, H. C. (2006). Cultural intelligence in organizations. Group \& Organization Management, 31(1), 20-26. https://doi.org/10.1177/1059601105275253

Ünal, S. (2014). Turkey's unexpected guests: Foreign immigrants and refugees experience in the context of "other". Journal of World of Turks, 6(3), 65-89.

Vedder, P., Horenczyk, G., Liebkind, K., \& Nickmans, G. (2006). Problems in ethno-cultural diverse educational settings and strategies to cope with these challenges. Educational Research Review, 1(2), 157-168.

Wubbels, T., Den Brok, P., Veldman, I., \& Van Tartwijk, J. (2006). Teacher interpersonal competence for Dutch secondary multicultural classrooms. Teachers and Teaching: Theory and Practice, 12(4), 407-433. https://doi.org/10.1080/13450600600644269 